\title{
The Predominance of Literacy Activities in Urban Early Childhood Education
}

\author{
Daoying Liu ${ }^{1, *}$, Linda Channell ${ }^{2}$ \\ ${ }^{1}$ School of Foreign Languages, Nantong University, China \\ ${ }^{2}$ College of Education and Human Development, Jackson State University, USA
}

Copyright (C) 2015 by authors, all rights reserved. Authors agree that this article remains permanently open access under the terms of the Creative Commons Attribution License 4.0 International License

\begin{abstract}
The purpose of this paper is to explore the predominance of literacy activities within the homes of African American toddlers in an urban setting in Mississippi. The data were collected through a Likert survey from parent participants in daycares, preschools, and churches, as well as institutions from five different parts of Jackson MS. The results indicate that reading to/with toddlers is the most predominant literacy activity that parents conducted within the homes of African American toddlers. Taking toddlers to the library is the least of literacy activities parents conducted to enhance their children's literacy development. This study is able to help parents engage more in their children's literacy development at home and develop early childhood education programs for parents.
\end{abstract}

Keywords Literacy Activities, Parental Involvement, Toddler's Literacy Development

\section{Introduction}

Children are one of the most important assets for a country, and they are also the nation's future. The global competitiveness of a nation is in large part determined by the success of children's literacy development level. Children's literacy is an essential indicator of the whole nation's literacy level, and the stability of the world's most powerful economic entity is largely determined by the next generation's ability to read and write well (Clifton [1]). The first five years of a child's life lay the groundwork for the future, and the physical, emotional, and intellectual development received during these early childhood years impact the degree of success that a child will achieve (U.S. Department of Education [2]). Literacy is composed of a large range of skills and abilities, it can have a comprehensive and strong impact on one's future success, and it is also a national concern to engage toddlers effectively in literacy activities and improve their levels of literacy skills in the early years. Preparation for a promising future and career success starts from very early years, even birth, and lots of researchers have indicated that high quality care and education during early childhood can benefit a child throughout his or her school career (Wright, Diener, \& Kay [3]). Early preparation for a toddler can lay a solid foundation for the child's future literacy development which can help him or her in school success and career achievement.

A Southern Educational Fund research report [4] showed that most southern states including Mississippi already lag behind the rest of the nation in academic achievement. In the NAEP's 2009 examinations for 4th grade students, the lowest average composite score of 223 came from African American students in the southern states. Based on the data from this report, no preschooling of three and four-year-olds accounts for $47 \%$ in Mississippi. Low-performing students are a potential challenge for all educators in the nation, and the number of low-performing students in Mississippi has established a pattern that could shape the state's entire performance. So Mississippi generally scores as one of the lowest states among the nation on the literacy test. Families do not play a role as they are supposed to in Mississippi urban settings. Many parents, particularly those low-income parents in the urban Mississippi setting, lack the time, skills, and information to be effective facilitators in the literacy development for children in the early life. Young children benefit a lot when their family members engage, connect, and are involved in ways that help them learn, grow, and feel secure within home environment (Lawrence-Lightfoot [5]). In Mississippi, the availability of developmentally appropriate literature is very limited in the African American communities due to poverty and lack of parental engagement in the literacy activities. The purpose of this study is to explore the predominance of literacy activities within the homes of African-American toddlers and how their parents engage in literacy activities.

\section{Literature Review}

Parental involvement is one of the most important issues in education, and it is also an important integral part of 
education. It consists of different forms of parental participation in children's literacy development, education and with schools. Parental involvement can refer to parents supporting their children's schooling by attending parent-teacher conferences, attending school activities, helping with children's school work, monitoring children's home work or actively tutoring their children through interaction at home. Many researchers suggest that strong parental involvement has a close and positive relationship with a child's readiness and success in academic performance, school attendance, positive attitudes toward education, and entry into post-secondary education (Epstein \& Dauber [6]; Zellman \& Waterman [7]). Informal education such as parental involvement in out of school time or at home is an integral part of formal education; it has a positive impact on the formal education provided at school. Olaniyi and Mageshni [8] showed that parental involvement positively correlated with students' academic achievement.

Henderson and Berla [9] conducted research covering 66 studies, reviews, and reports on the benefits of parent involvement in children's academic achievement, and they concluded that the accurate predictor of student achievement is the extent to which the family is involved in his or her education. When parents are involved in the toddlers' literacy development, they will have better self-discipline and show more motivation to reading and writing, and they also can make more achievements in academic areas.

Studies have shown that early language development affects later reading achievement (Craig, Conner, \& Washington [10]). Preschool vocabulary is a major predictor of subsequent school success (Rowe, Raudenush, \& Golden-Meadow [11]). Interaction levels and vocabulary size between parents and children are positively correlated as shown in this seminal study by Hart and Risley [12]. The authors studied 42 toddlers (34-36 months) and their parents regarding time spent with each other, the amount of hours each parent worked, and the educational level of the parents. The results show the toddlers' vocabulary consisted almost entirely of words found in their parents' vocabulary ( $86 \%$ to $98 \%$ ). Quantity of language input is an important determinant of vocabulary size. The more language input toddlers hear at home with their parents in the natural settings, the larger their subsequent vocabularies will be. Hurtado, Marchman \& Fernald [13] conducted a longitudinal study on mother's speech at 18 months in relation to toddlers' speech processing efficiency and reported vocabulary at 18 and 24 months. The results show that children whose mothers provided more input at 18 months knew more words and were faster in word recognition at 24 months. The results indicate that language input from parents both influences toddlers' vocabulary knowledge and shapes their lexical processing skills in ways that enable more efficient uptake of relevant information in the speech signal.

However, parents who suffered from poverty or lived with social-economic stress, experience higher levels of emotional strain and mental health problems (McLoyd [14] [15]), which can impair their ability to engage with and support children and increase their likelihood of using harsh or punitive parenting practices (Conger, Vonger, Elder, Lorenz, Simons, \& Whitebeck, [16]; McLoyd [15]). The discontinuity between many ethnic minority parents' indigenous cultural/social capital and mainstream culture and institutions can also influence parenting and family involvement (Delgado-Gaitan [17]; Moll [18]). Zinn et al. [19] identify social location or social class as another source of discontinuity for ethnic minority groups. So, some educators don't believe that African-American parents can conduct effective involvement in their children's literacy activities and care about the children's education (Thompson [20]). Inner-city African-American parents generally evidence patterns of low school involvement (Desimone [21]).

Based on the previous research on the parental involvement in the toddlers' literacy activities within the homes of African American families, this study is to explore the predominance of literacy activities within the homes of African-American toddlers and how their parents engage in literacy activities in an urban Mississippi setting.

\section{Methodology}

A quantitative approach was utilized in this study to explore frequencies, percentages and averages of the variables. A quantitative research method involves the use of numerical data to summarize, describe, and explore relationships among traits (McMillian \& Wergin [22]). The approach in this study involved studying parental involvement in literacy activities in the homes of African-American toddlers in the urban Jackson area of Mississippi. The participants were recruited from a variety of sources, mainly from preschools, but also from churches, after schools, and staff and faculty of institutions in the Jackson area Mississippi. All the participants were African-American parents or guardians who had toddlers aged between 12 months and 36 months in Jackson area. 420 surveys were distributed to the parents or caregivers who had toddlers at home in five different parts of Jackson Mississippi. Only 92 parents or caregivers had returned those surveys back to our research group. Among those 92 surveys, 25 forms were not appropriately filled, and they were not counted as effective surveys in final analysis. A total of 67 surveys were finally collected from parents or guardians in the study. 
Table 1. Demographic Information of Participants

\begin{tabular}{|c|c|c|c|}
\hline Item & Descriptor & $\mathrm{N}$ & $\%$ \\
\hline \multirow{3}{*}{ Relationship to child } & Parent & 57 & 85.1 \\
\hline & Grandparent & 8 & 11.9 \\
\hline & Guardian & 2 & 3.0 \\
\hline \multirow{2}{*}{ Parent's Gender } & Female & 48 & 71.6 \\
\hline & Male & 19 & 28.4 \\
\hline \multirow{4}{*}{ Child's early educational experience } & Stayed at home & 18 & 26.9 \\
\hline & Someone else's home & 6 & 9.0 \\
\hline & Daycare center & 24 & 35.8 \\
\hline & Preschool & 19 & 28.4 \\
\hline \multirow{7}{*}{ Parent's Age } & Under 20 & 2 & 3.0 \\
\hline & $21-25$ & 6 & 9.0 \\
\hline & $26-30$ & 14 & 20.9 \\
\hline & $31-35$ & 17 & 25.4 \\
\hline & $36-40$ & 15 & 22.4 \\
\hline & $41-45$ & 4 & 6.0 \\
\hline & Over 45 & 9 & 13.4 \\
\hline \multirow{5}{*}{ Home location in Jackson } & East Jackson & 5 & 7.5 \\
\hline & West Jackson & 12 & 17.9 \\
\hline & North Jackson & 26 & 38.8 \\
\hline & South Jackson & 9 & 13.4 \\
\hline & Rural Jackson Area & 15 & 22.4 \\
\hline \multirow{5}{*}{ Parent's educational level } & High school diploma or GED & 15 & 22.4 \\
\hline & Some college or special training & 7 & 10.4 \\
\hline & Associates degree & 5 & 7.5 \\
\hline & 4-year college degree & 23 & 34.3 \\
\hline & Master's or Advanced degree & 17 & 25.4 \\
\hline \multirow{5}{*}{ Family Income } & Less than $\$ 25,000$ & 21 & 31.3 \\
\hline & $\$ 25,001-\$ 50,000$ & 35 & 52.2 \\
\hline & $\$ 50,001-\$ 75,000$ & 5 & 7.5 \\
\hline & $\$ 75,001-\$ 100,000$ & 6 & 9.0 \\
\hline & More than $\$ 100,000$ & 0 & 0 \\
\hline
\end{tabular}

The sample population, as shown in Table 1, was composed of 67 African American parents or guardians living in different parts of the Jackson, Mississippi, area. Table 1 indicates the description of demographic characteristics of parents in this study. It also provides the general information of participants involved in the literacy development of their children in the Jackson area. Of the 67 participants in this study, 57 were parents, 8 were grandparents, and 2 were guardians. The parents accounted for $85.1 \%$ of the participants in this study. Among all the participants, 48 were females and 19 were males. Female participants accounted for $71.6 \%$ of total population in the study. The age of participants ranged from 21 to over 45 , while very few parents ( 2 parents) were under 20 years old. The age of most parent participants ranged from 26 to 40 which accounted for $68.7 \%$.
As to the location of the Jackson area, 5 participants (7.5\%) were from East Jackson, 12 (17.9\%) from West Jackson, 26 (38.8\%) from North Jackson, 9 (13.4\%) from South Jackson and $15(22.4 \%)$ from the rural Jackson area. The biggest proportion of participants was from North Jackson, accounting for $38.8 \%$ of the total participants. As to educational levels of the sample population, 40 participants $(59.70 \%)$ had completed a 4-year college/university or higher degree. 5 (7.5\%) had associate's degree. $7(10.4 \%)$ had some college or special training. 15 participants $(22.4 \%)$ had high school diploma or lower education.

The family income for the participants in this study ranged from less than $\$ 25,000.00$ to more than $\$ 75,001.00$. More than half of participants $(52.2 \%)$ reported that their family income was between $\$ 25,001.00-\$ 50,000.00 .21$ participants self- reported that their family income was less than 
$\$ 25,000.00$, accounting for $31.3 \%$.

Table 2. Number of Adults and Children Living in the Household

\begin{tabular}{cccc}
\hline Item & Descriptor & Mean & SD \\
\hline \multirow{3}{*}{ Number of adults } & 1 & & \\
& 2 & 1.79 & 0.73 \\
& 3 & & \\
Number of children & 4 & & \\
& 1 & & \\
& 2 & & \\
& 3 & & \\
\hline
\end{tabular}

From Table 2, the number of adults and number of children living in the African American household were examined in this study. Of 67 parent participants, 24 (35.8\%) reported they were single parents in the family. Of 67 parent participants, $35(52.2 \%)$ reported that they had two adults living in the household. Extended families consisting of 3 and 4 adults in the household accounted for $12 \%$ in this survey, and they were a little more than one tenth. The average number of adults living in the home of African American toddlers in the Jackson area was 1.79. Single parent families accounted for more than one third in this survey, and the majority of single parents were single mothers.

As for the number of children of the 67 parent participants, $19(28.4 \%)$ reported they had one child in the home, 24 (35.8\%) reported 2 children, $13(19.4 \%)$ reported 3 children, $7(10.4 \%)$ reported 4 children, and $4(6.0 \%)$ reported 5 children. The average number of children living in the homes of African American toddlers in the Jackson area was 2.30.

Table 3. Reading is an Activity I Enjoy

\begin{tabular}{cccc}
\hline Items & Descriptor & $\mathrm{N}$ & $\%$ \\
\hline & strongly agree & 28 & 41.8 \\
& agree & 25 & 37.3 \\
Reading is an activity I enjoy & somewhat agree & 14 & 20.0 \\
& disagree & 0 & 0 \\
& strongly disagree & 0 & 0 \\
\hline
\end{tabular}

The data in Table 3 illustrate the descriptive features for parents on how they think of reading as an activity they enjoy in the home environment in the Jackson, Mississippi, area. The purpose of this item was to explore how parents established a literacy environment in the homes of African American toddlers in the Jackson, Mississippi, area. 53 out of 67 parent participants $(79.1 \%)$ reported they strongly agreed or agreed that reading was an activity they enjoyed at home. 14 out of 67 parent participants (20.0\%) reported they somewhat agreed reading was an activity they enjoyed.
Nobody reported that he or she disagreed or strongly disagreed that reading was an activity he or she enjoyed in the home of African American toddlers in the Jackson area. All the choices fell in the first three as "strongly agree," "agree," and "somewhat agree." The average score of this item in the survey was 1.93, and it indicates reading is one of the most common literacy activities parents conducted in the homes of African American toddlers.

The participants responded to a list of multiple choices in a 4-point Likert-type Scale survey. A reliability analysis was run with SPSS 22.0 to examine if this survey was a reliable measure of items in this study. Cronbach's Alpha was 0.954, and this indicated that the survey was a reliable measure of the items. The items of the surveys covered the frequencies of literacy activities parents involved. This measure does not require parents to take a stand on a particular item or force parents to respond with a concrete "yes" or "no" answer. Furthermore, the responses from parents or guardians were easy to code and decode in the process of data collection and data analysis because each number represents a specific response. The Likert-type Scale in this study was convenient to be handled and inexpensive for data collection, and the researcher can easily spread out those surveys to the targeted participants. A list of 20 items were included in the Likert-type Scale survey and they covered the following dimensions: reading to/with toddlers, asking questions about the story in reading, identifying letters in toddlers' names, writing alphabet letters and having toddlers trace them, taking toddlers to the library, using letters to teach names, encouraging toddlers to talk about the story, purchasing books, asking toddlers to predict what will happen next in reading, singing alphabet songs, defining unfamiliar words or pictures, playing games with toddlers, encouraging toddlers to write their names, encouraging toddlers to use different materials, pointing to a word that a picture stands for, pointing out the title in reading, asking toddlers to read aloud, pointing to the printed words in reading, watching and discussing educational TV programs and pointing out different types of printed materials. For the involvement of literacy activities from parents, the Likert-type Scale in this study was scored as $1=$ rarely or never, $2=1$ to 2 times per month, $3=1$ to 2 times per week, and $4=3$ or more times per week. The purpose of this 4-point Likert-type Scale was to examine the types and frequencies of educational or literacy activities parents or guardians selected for their toddlers in the home.

All the dimensions were designed to test parental involvement in literacy activities and their frequency of involvement in the toddler's literacy development in the urban setting. All of the responses were analyzed using the Statistical Package for Social Sciences (SPSS) 22.0 for Windows. The demographic information for parents who participated in this research project was also collected with a questionnaire, and the information served as independent variables in this study. 


\section{Results}

Table 4. Means and Standard Deviations of Parental Involvement in Literacy Activities

\begin{tabular}{|c|c|c|c|c|c|c|c|c|c|c|}
\hline \multirow{2}{*}{ Item } & \multicolumn{2}{|c|}{$\begin{array}{c}\text { Rarely or } \\
\text { never }\end{array}$} & \multicolumn{2}{|c|}{$\begin{array}{l}1 \text { to } 2 \text { times } \\
\text { per month }\end{array}$} & \multicolumn{2}{|c|}{$\begin{array}{l}1 \text { to } 2 \text { times } \\
\text { per week }\end{array}$} & \multicolumn{2}{|c|}{$\begin{array}{c}3 \text { to more times } \\
\text { per week }\end{array}$} & \multirow[t]{2}{*}{ Mean } & \multirow[t]{2}{*}{$\mathrm{SD}$} \\
\hline & $\mathrm{N}$ & $\%$ & $\mathrm{~N}$ & $\%$ & $\mathrm{~N}$ & $\%$ & $\mathrm{~N}$ & $\%$ & & \\
\hline Reading with toddlers & 2 & 3.0 & 4 & 6.0 & 34 & 50.7 & 27 & 40.3 & 3.28 & 0.71 \\
\hline Asking questions & 3 & 4.5 & 9 & 13.4 & 31 & 46.3 & 24 & 35.8 & 3.13 & 0.81 \\
\hline Identifying letters & 9 & 13.4 & 9 & 13.4 & 25 & 37.3 & 24 & 35.8 & 2.96 & 1.02 \\
\hline Writing alphabet letters & 7 & 10.4 & 9 & 13.4 & 30 & 44.8 & 21 & 31.3 & 2.97 & 0.94 \\
\hline Visiting library & 10 & 14.9 & 19 & 28.4 & 25 & 37.3 & 13 & 19.4 & 2.61 & 0.97 \\
\hline Using letter games & 7 & 10.4 & 11 & 16.4 & 26 & 38.8 & 23 & 34.3 & 2.97 & 0.97 \\
\hline Talking about stories & 4 & 6.0 & 7 & 10.4 & 36 & 53.7 & 20 & 29.9 & 3.07 & 0.80 \\
\hline Purchasing books & 3 & 4.5 & 18 & 26.9 & 19 & 28.4 & 27 & 40.3 & 3.04 & 0.93 \\
\hline Predicting story plots & 10 & 14.9 & 7 & 10.4 & 29 & 43.3 & 21 & 31.3 & 2.91 & 1.01 \\
\hline Singing alphabet songs & 7 & 10.4 & 11 & 16.4 & 18 & 26.9 & 31 & 46.3 & 3.09 & 1.03 \\
\hline Describing words & 3 & 4.5 & 9 & 13.4 & 25 & 37.3 & 30 & 44.8 & 3.22 & 0.85 \\
\hline Playing literacy games & 8 & 11.9 & 13 & 19.4 & 35 & 52.2 & 11 & 16.4 & 2.73 & 0.88 \\
\hline Writing the names & 2 & 3.0 & 4 & 6.0 & 34 & 50.7 & 27 & 40.3 & 3.28 & 0.71 \\
\hline Using literacy materials & 3 & 4.5 & 6 & 9.0 & 29 & 43.3 & 29 & 43.3 & 3.25 & 0.80 \\
\hline Telling picture meanings & 3 & 4.5 & 10 & 14.9 & 30 & 44.8 & 24 & 35.8 & 3.12 & 0.83 \\
\hline Reading book covers & 4 & 6.0 & 9 & 13.4 & 35 & 52.2 & 19 & 28.4 & 3.03 & 0.82 \\
\hline Reading aloud & 6 & 9.0 & 8 & 11.9 & 31 & 46.3 & 22 & 32.8 & 3.03 & 0.90 \\
\hline Reading pointed words & 3 & 4.5 & 8 & 11.9 & 37 & 55.2 & 19 & 28.4 & 3.07 & 0.77 \\
\hline Discussing TV program & 2 & 3.0 & 13 & 19.4 & 28 & 41.8 & 24 & 35.8 & 3.10 & 0.82 \\
\hline Identifying printed materials & 4 & 6.0 & 10 & 14.9 & 35 & 52.2 & 18 & 26.9 & 3.00 & 0.82 \\
\hline
\end{tabular}

Note: $\mathrm{N}=67$

Table 4 describes the percentage, arithmetic mean and standard deviation of items related to parental involvement in toddler's literacy activities. Respondent parent participants showed great differences in the engagement of literacy activities with their toddlers. The highest percentage of parental involvement (46.3\%) in the literacy activities for "three to more times per week" was singing alphabet songs with their toddlers. The lowest percentage of parental involvement (16.4\%) in the activities for "three to more times per week" was playing literacy games with their toddlers. The highest percentage of parental involvement (55.2\%) for "one to two times per week" was reading while pointing to the printed words to their toddlers. The lowest percentage of parental involvement (26.9\%) in the literacy activities for "one to two times per week" was singing alphabet songs with their toddlers. The highest percentage of parental involvement (28.4\%) in the activities for "one to two times per month" was taking the child to the library to look at books. The lowest percentage items of parental involvement $(6.0 \%)$ in the activities for "one to two times per month" were reading picture books and stories with their toddlers and encouraging children to write their names. The highest percentage items of parental involvement (14.9\%) in the activities for "rarely or never" were taking their children to the library to look at books and predicting what will happen next in reading. The lowest percentage items of parental involvement (3.0\%) in the activities for "rarely or never" were reading picture books and stories with their toddlers, encouraging their children to write their own names, and watching educational TV shows to discuss with their children.

Table 5. Comparisons of Parental Involvement in Literacy Activities

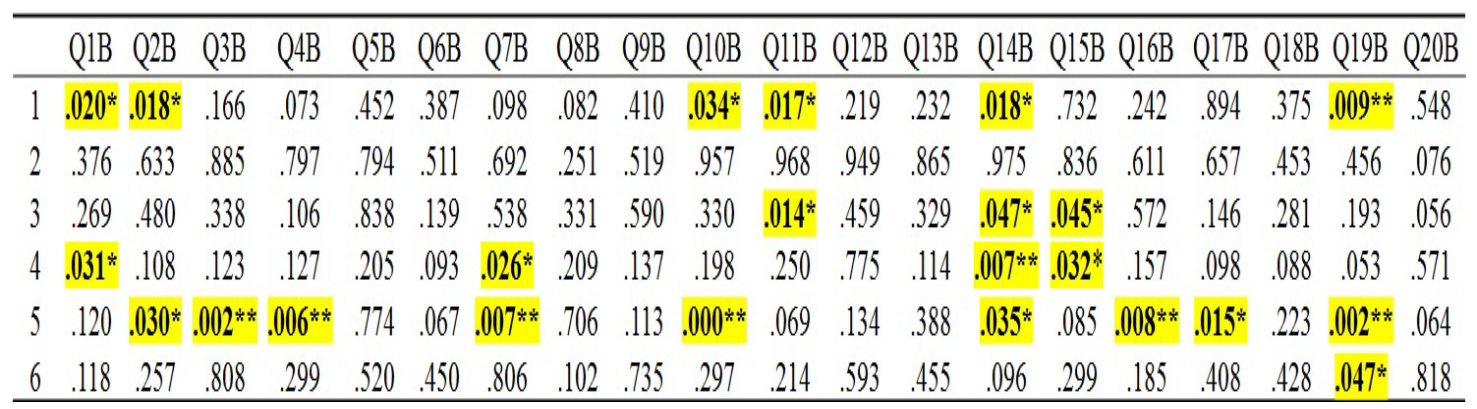

Note: Q1B Q20B represent 20 statements of parental involvement in literacy activities in the homes of African American toddlers in the Jackson, Mississippi, area. 1 represents parent's age group. 2 represents parent's home location in Jackson area. 3 represents parent's educational level. 4 represents the number of adults living in the household. 5 represents the number of children living in the household. 6 represents family income.

** Significance at the 0.01 level (2-tailed)

* Significance at the 0.05 level (2-tailed) 
In Table 5, six variables were selected as factors which affect parental involvement in toddlers' literacy development, and they are parent's age, parent's home location, parent's educational level, numbers of adults living in the household, numbers of children living in the household and family income. A Kruskal-Wallis test was conducted to determine whether parental involvement in literacy activities varied as these six variables. Table 5 indicated that the differences in parental involvement toward literacy activities were found in these five areas: parent's age, parent's educational level, number of adults and children living in the household and family income. Table 5 also illustrated that parent's home location in the different parts of Jackson did not affect their involvement significantly in literacy activities in the homes of African American in this survey.

From Table 5, parent's age is one of the most important factors affecting how parents are involved in the toddlers' literacy activities. The impact of parent's age groups on parental involvement in the toddlers' literacy activities lied in reading picture books and stories with toddlers, asking toddlers questions about the story in reading, singing alphabet songs with toddlers, pausing to define or describe unfamiliar words or pictures when reading, encouraging toddlers to use different materials for writing or drawing and watching and discussing educational TV programs together. The $p$ values are $0.020,0.018,0.034,0.017,0.018$ and 0.009 respectively.

Parent's educational level had significantly different impact on their involvement in pausing to define or describe unfamiliar words or pictures when reading, encouraging toddlers use different materials for writing or drawing and stopping to point to a word that a picture stands for when reading. The according $\mathrm{p}$ values are $0.014,0.047$, and 0.045 respectively. In addition, family income is one of those factors affecting how parents are involved in their children's literacy development. Parents had significantly different involvement in watching and discussing educational TV programs together with their toddlers, and its $\mathrm{p}$ value is 0.047 .

From this Table, it is found that numbers of adults living in the household had a potential impact on parental involvement in their toddlers' literacy activities. The parents had significantly different involvement in reading picture books and stories with toddlers, encouraging toddlers to talk about the story during and after reading, encouraging toddlers use different materials for writing or drawing and stopping to point to a word that a picture stands for when reading. The according $p$ values are $0.031,0.026,0.007$ and 0.032 respectively. The numbers of children living in the household are also an important factors affecting how parents are involved in their toddlers' literacy activities. Parents had significantly different involvement in asking toddlers questions about the story in reading, pointing to and identifying letters in toddler's name, writing alphabet letter and having toddlers to trace, encouraging toddlers to talk about the story during and after reading, singing alphabet songs with toddlers, encouraging toddlers to use different materials for writing or drawing, pointing out the title of book covers when reading, asking toddlers to read aloud something he/she wrote, and watching and discussing educational TV programs. The according $\mathrm{p}$ values are 0.030 , $0.002,0.006,0.007,0.000,0.035,0.008,0.015$ and 0.002 respectively.

\section{Discussion}

Based on the survey conducted in the study, the highest percentage of parental involvement in literacy activities three or more time a week is singing alphabet songs with their toddlers. Defining or describing unfamiliar words or pictures in reading is the second common literacy activity that parents get involved in with their toddlers three or more time a week in the literacy development. The highest means of parental involvement in toddlers' literacy activities lay in reading picture books and stories with toddlers and encouraging toddlers to write their names, with both of them being 3.28. This indicates that reading picture books and stories and encouraging toddlers to write their names are the most frequent literacy activities parents conducted in the homes of African American toddlers in the Jackson area.

Interaction is one of the most important strategies for toddlers to explore the world and develop their literacy skills. Toddlers' literacy development is associated with interactions with adults and their environments (Vygotsky [23]; Bruner [24]; Bronfenbrenner [25]). Vygotsky also believed that interaction served as an instrument for toddlers to transit knowledge to construct their own knowledge from external to internal behaviors (Dorn [26]). The interactions were illustrated in this study from two dimensions: one is parent-child interaction, and the other is toddlers' interaction with home environments. Parent-child interaction is a key predictor of early literacy skills. Parents interact with their toddlers in daily life, and this interaction can shape the beliefs of what should be valued in the literacy development of toddlers. According to the survey, the lowest percentage of parental involvement in literacy activities three or more time a week is to play games with toddlers. Playing games is the least of the literacy activities parents considered to be "absolutely important," and it is also one of the least of the literacy activities parents conducted to enhance children's development in African American homes. Playing literacy games is an excellent opportunity for parents and children to interact with each other. The survey indicated that African American parents in the Jackson area were reluctant to initiate this literacy activity in the homes. This could lead to less direct interactions between parents and toddlers.

The second dimension of interaction in the survey was focused on toddlers and their environments. Based on the survey, the lowest mean of parental involvement in toddlers' literacy activities was taking toddlers to the library, and its value is 2.61 . So, taking toddlers to the library is one of the least valued literacy activity parents conducted with their toddles for African American parents in the Jackson area. 
Libraries provide access to information about culture, society, economy, and history, and it plays an important role in promoting children's literacy (Weibel [27]). The library can provide various types of stories and books, and children can learn and recognize printed words, sight words and high frequency words, and match words with printed text in the library (Dodge et al [28]). The library provides a large variety of learning facilities and materials, and it is also an ideal place for parents and toddlers to interact with each other through the resources in their collections. Taking toddlers to the libraries also can give an opportunity for toddlers to decide on their books in accordance with their own interests. Table 5 indicated that parent participants don't have more opportunities to be exposed to a variety of books in the neighborhood or city libraries. The maximum percentage of parental involvement in toddlers' activities three or more times a week is $46.3 \%$, while the lowest is $16.4 \%$. None of percentages of parental involvement is more than $50 \%$, and it indicates that parent participants in the Jackson area generally have low involvement in their toddlers' literacy development.

Home-based involvement in literacy activities is one of the direct ways for parents to actively engage in toddler's learning and literacy development in the home setting. A meta-analytic study was conducted on 17 studies in 1995, and the results indicated an overall positive association between parental reading to or with their children and children's emergent literacy development (Bus, Van Ijzendoorn and Pellegrini [29]). The data in this study indicated that African American parents realized how reading to or with toddlers play a role in the literacy development, but they did not conduct adequate manipulations engaging with their toddlers' reading activities in the homes. The percentage of parental involvement in reading to or with toddlers is still very low in the urban setting.

Home environments including parent's age, parent's home location in different parts of Jackson, level of parental education, family size and socio-economic status affect parental involvement in toddler's literacy development. As to parental involvement in literacy activities in the homes of African American toddlers in the Jackson area, the differences were found in the following five areas: parent's age, parent's home location in Jackson, number of adults and children living in the household and family income.

Age is one of the key factors to impact how parents were involved in literacy activities in the homes of African American toddlers in Jackson area Mississippi. There is a significant difference existing in parental involvement in literacy activities as it relates to parent's age. Parents with different ages tend to have different involvement in reading picture books and stories with toddlers, asking toddlers questions about the story in reading, singing alphabet songs with toddlers, pausing to define or describe unfamiliar words or pictures when reading, encouraging toddlers to use different materials for writing or drawing and watching and discussing educational TV programs together. Parents with age of 31-35 were more likely to engage in reading picture books and stories with their toddlers, asking toddlers questions about the story in reading and watching and discussing educational TV programs together three or more times per week. Parents with age under 20 tended to be involved in singing alphabet songs with toddlers and pausing to define or describe unfamiliar words or pictures when reading. Parent with age of 26-30 were more likely to encourage toddlers to use different materials for writing or drawing.

Parent's educational level has a potential impact on their involvement in the literacy activities in the homes of African American parents in Jackson area. There is a significant difference existing in parental involvement in pausing to define or describe unfamiliar words or pictures when reading, encouraging toddlers use different materials for writing or drawing and stopping to point to a word that a picture stands for when reading. Parents with high school diploma or GED were more likely to define or describe unfamiliar words or pictures for their toddlers in reading three or more times per week while parents with master's or advanced degree tended to encourage toddlers use different materials for writing or drawing and stopping to point to a word that a picture stands for when reading three or more times per week. Parents with associate degree tended to rarely or never conduct these three literacy activities in the homes.

There is a significant difference existing in parental involvement in literacy activities as it relates to the number of adults living in the household of African American toddlers. From Table 5, the parents had significantly different involvement in reading picture books and stories with toddlers, encouraging toddlers to talk about the story during and after reading, encouraging toddlers use different materials for writing or drawing and stopping to point to a word that a picture stands for when reading. Parents from the families of 2 adults were more likely to conduct these literacy activities with their toddlers three or more times per week while parents from the families of 4 rarely or never conducted these activities in the home. The number of children living in the household is also one of the most important factors affecting parental involvement in the literacy activities. This Table also indicates parents had significantly different involvement in asking toddlers questions about the story in reading, pointing to and identifying letters in toddler's name, writing alphabet letter and having toddlers to trace, encouraging toddlers to talk about the story during and after reading, singing alphabet songs with toddlers, encouraging toddlers to use different materials for writing or drawing, pointing out the title of book covers when reading, asking toddlers to read aloud something he/she wrote, and watching and discussing educational TV programs. Generally, parents with only one child in the household were more likely to be involved three or more times per week in these literacy activities.

In this research, the results also indicate there is a positive relationship between parental involvement and their material 
family conditions. Family income affects how parents engage in with their toddlers' literacy development, especially in watching and discussing educational TV programs. The results indicate that parents have significant difference in conducting literacy activities concerning educational TV programs. Those parents from higher income families are more actively involved in the children's literacy development using TV programs as an effective educational activity. There are lots of researches covering the relationship between family socioeconomic status and children's literacy activities. From as early as the 1970s, the social class dimension of literacy practices in the home was considered to be a major influence on young children's literacy development. A mostly accepted opinion in the researches holds that children from higher socioeconomic status families performs better in academic achievement than those from lower socioeconomic status families (Duncan, Yeung, Brooks-Gunn \& Smith [30]). Parents who have higher family incomes are able to provide better and richer literacy environment for their toddlers in the development.

\section{Conclusions}

Reading to/with toddlers is the most predominant literacy activity that parents/guardians conducted three or more times per week within the homes of African American toddlers. Taking toddlers to the library is the least of the literacy activities parents conducted. Home environments including parent's age, parent's home location in different parts of Jackson, level of parental education, family size and socio-economic status affect parental attitudes toward literacy activities and involvement in their toddler's literacy development.

Recommendations were raised pertaining to this research on African American parents, early childhood education professionals and practitioners to help parents better engage in the toddler's literacy development. Attempts are suggested to be made in the parent's training programs to enhance their involvement in toddler's literacy development with the help of technology. Enormous efforts should be made in the parent's training programs in enhancing parent's involvement in the toddler's literacy activities, especially in how to establish a rich literacy environment and how to interact with children better in the homes. Literacy development is not only confined to traditional activities in the homes. Technology is suggested to be introduced to promote a parent's involvement in the literacy development. School-parent programs are suggested to be developed in an urban early childhood setting to better serve the parents who are still in trouble with their toddler's involvement. Preschools, communities, and governments should be encouraged to help parents engage in their toddlers' literacy activities to reduce the negative influences by age, educational level, home location, family size, and family income. Early childhood education theoretical professionals and practitioners should build a long-term intervention program to monitor and provide aids for parents to improve effectiveness of their involvement in the toddlers' literacy development.

This study is limited to the number of participants in one urban setting in the Jackson area in Mississippi, and this could limit the generalizability of results beyond areas of similar demographics. In addition, a certain percentage of participants are economically impoverished, and they have difficulty in reading and writing. A recommendation for further research is that a follow-up study to design an effective parents' training program to improve their involvement in toddler's literacy development. This training program should be based on the characteristics of parents in the Jackson area as it related to their age, educational level, home location in the Jackson area, family size and family income. It is also recommended that a research on the types of questions be conducted with interviews on parents or guardians in the homes of African-American toddlers in the Jackson, Mississippi.

\section{REFERENCES}

[1] Clifton, J. (2011). The Coming Jobs War. New York, NY: Gallup Press.

[2] U.S. Department of Education. (1992). Starting school ready to learn. Washington, DC: Resource Team of National Education Goal 1.

[3] Wright, C., Diener, M., \& Kay, S.C. (2000). School readiness of low-income children at risk for school failure. Journal of Children \& Poverty, 6(2), 99-117.

[4] Southern Education Foundation. (2010). A New Diverse Majority: Students of Color in the South's Public Schools. GA: Atlanta

[5] Lawrence-Lightfoot, S. (2003). The essential conversation: What parents and teachers can learn from each other. New York, NY: Ballantine Books.

[6] Epstein, J. L., \& Dauber, S. L. (1991). School programs and teacher practices of parent involvement in inner-city elementary and middle schools. Elementary School Journal, 91(3), 289-305.

[7] Zellman, G., \& Waterman, J. (1998). Understanding the impact of parent school involvement on children's educational outcomes. Journal of Educational Research, 91(6), 370-380.

[8] Olaniyi, B., \& Mageshni, N. (2008). Parental Involvement and Children's Academic Achievement in a South Africa Setting. Journal of Psychology in Africa, 18(2), 275.

[9] Henderson, A. T., \& Berla, N. (Eds.). (1994). A new generation of evidence: The family is critical to student achievement (A report from the National Committee for Citizens in Education). Washington, DC: Center for Law and Education

[10] Craig, H. J., Conner, C. M., \& Washington, J. A. (2003). Early positive predictors of later reading comprehension for 
African-American students: A preliminary investigation. Language, Speech, and Hearing Services in Schools, 34, 31-43.

[11] Rowe, M. L., Raudenbush, S. W., \& Goldin-Meadow, S. (2012). The pace of early vocabulary growth helps predict later vocabulary skill. Child Development,83(2), 508-525. doi:10.1111/j.1467-8624.2011.01710.x.

[12] Hart, B., \& Risley T. R. (1995) Meaningful differences in the everyday experience of young American children. Baltimore, MD: Paul Broookes.

[13] Hurtado N., Marchman, V. A., \& Fernald A. (2008). Does input influence uptake? Links between maternal talk, processing speed and vocabulary size in Spanish-learning children. Development Science, 11(6), F31-F39.

[14] McLoyd, V. C. (1990). The impact of economic hardship on black families and children: Psychological distress, parenting, and socioemotional development. Child Development, 61, 311-346.

[15] McLoyd, V. C. (1998). Socioeconomic disadvantage and child development. American Psychologist, 53, 185-204.

[16] Conger, R. D., Vonger, K. J., Elder, G. H., Lorenz, F. O., Simons, R. L., \& Whitebeck, L.B. (1992). A family process model of economic hardship and adjustment of early adolescent boys. Child Development, 63, 526-541.

[17] Delgado, G. C. (1991). Involving parents in the schools: A process of change for involving parents. American Journal of Educational, 100(1), 20-46.

[18] Moll, L. C. (1994). Literacy research in community and classrooms: A sociocultural approach. In R. B. Ruddell, M. R. Ruddell, \& H. Singer (Eds.), Theoretical models and processes of reading (4th ed.). Newark, DE: International Reading Association.

[19] Zinn, B., Maxine, and Wells, B. (2000). Diversity Within Latino Families: New Lessons for Family Social Science. New York: Oxford University Press.

[20] Thomson, G. L. (2003). Prediction in African American parents' and guardians' satisfaction with teachers and public schools. The Journal of Educational Research, 96(5), 277-286.

[21] Desimone, L. (1999). Linking parent involvement with student achievement: Do race and income matter? Journal of Educational Research, 93(1), 11-30.

[22] McMillan, J. H., \& Wergin, J. F. (2006). Understanding and evaluating educational research (3rd ed.). Upper Saddle River, NJ: Pearson.

[23] Vygotsky, L.S. (1978). Mind in society: The development of higher psychological processes. Cambridge, MA: Harvard University Press.

[24] Bruner, J. S. (1967). Studies in cognitive growth: A collaboration at the center for cognitive growth. New York, NY: John Wiley \& Sons.

[25] Bronfenbrenner, U. (1979). The ecology of human development: Experiments by nature and design. Cambridge, MA: Harvard University Press.

[26] Dorn, L. (1996). A Vygotskian perspective on literacy acquisition: talk and action in the child's construction of literate awareness. Literacy, Teaching and Learning, 2(2), $15-40$.

[27] Weibel, M. C. (1992). The library as literacy classroom: A program for teaching. Chicago, IL: American Library Association.

[28] Dodge, D., Colker, L., \& Heroman, C. (2002) Creative curriculum for preschool. Washington, DC: Teaching Strategies.

[29] Bus, A. G., van Ijzendoorn, M. H., \& Pellegrini, A. D. (1995). Joint book reading makes for success in learning to read: A meta-analysis on intergenerational transmission of literacy. Review of Educational Research, 65, 1-65.

[30] Duncan, G., Yeung, W.J., Brooks-Gunn, J., \& Smith, J.R. (1998). How much does childhood poverty affect the life chances of children? American Sociological Review, 63, 406-423. 